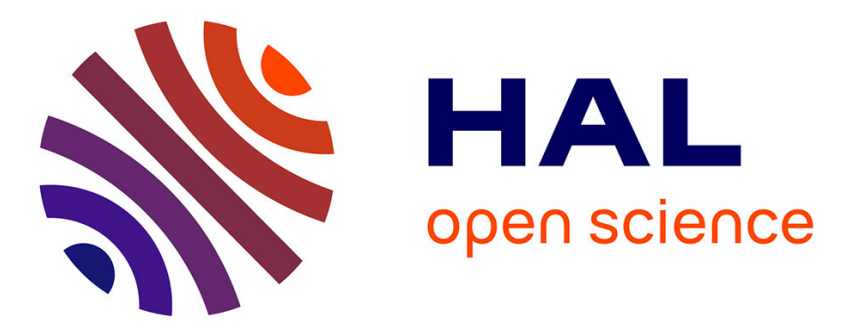

\title{
An adaptive approach to Failure Modes and Effects Analysis for Computer-Aided Inspection Planning
}

Shirin Mirdamadi, Ali Siadat, Jean-Yves Dantan, Lionel Roucoules

\section{To cite this version:}

Shirin Mirdamadi, Ali Siadat, Jean-Yves Dantan, Lionel Roucoules. An adaptive approach to Failure Modes and Effects Analysis for Computer-Aided Inspection Planning. IEEM-FMEA, Dec 2012, Hong Kong, China. pp.10. hal-01203433

\section{HAL Id: hal-01203433 https://hal.science/hal-01203433}

Submitted on 23 Sep 2015

HAL is a multi-disciplinary open access archive for the deposit and dissemination of scientific research documents, whether they are published or not. The documents may come from teaching and research institutions in France or abroad, or from public or private research centers.
L'archive ouverte pluridisciplinaire HAL, est destinée au dépôt et à la diffusion de documents scientifiques de niveau recherche, publiés ou non, émanant des établissements d'enseignement et de recherche français ou étrangers, des laboratoires publics ou privés. 


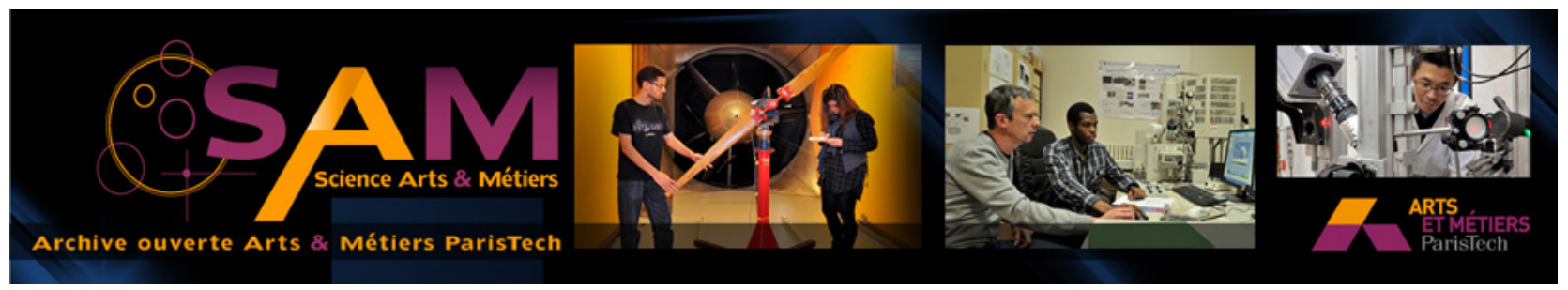

\section{Science Arts \& Métiers (SAM)}

is an open access repository that collects the work of Arts et Métiers ParisTech researchers and makes it freely available over the web where possible.

This is an author-deposited version published in: http://sam.ensam.eu

Handle ID: .http://hdl.handle.net/10985/10126

\section{To cite this version :}

Shirin MIRDAMADI, Ali SIADAT, Jean-Yves DANTAN, Lionel ROUCOULES - An adaptive approach to Failure Modes and Effects Analysis for Computer-Aided Inspection Planning - In: IEEM-FMEA, Chine, 2012-12-11 - IEEM-FMEA 2012 - 2012 


\title{
An adaptive approach to Failure Modes and Effects Analysis for Computer- Aided Inspection Planning
}

\author{
S. Mirdamadi ${ }^{1}$, A. Siadat ${ }^{1}$, J. Y. Dantan ${ }^{1}$, L. Roucoules ${ }^{2}$ \\ ${ }^{1}$ Arts et Métiers ParisTech, 4, rue Augustin Fresnel, 57070 Metz, France \\ ${ }^{2}$ Arts et Métiers - CER d'Aix-en-Provence, 2, cours des Arts et Métiers, 13617 Aix-en-Provence \\ (shirin.mirdamadi@ensam.eu)
}

\begin{abstract}
In robust design, the principle is to improve product quality minimizing the impacts of variations. Variability depends strongly on the set of explicit and implicit decisions taken during product design, selection of methods, processes and resources. This paper presents a new approach to decision making for inspection planning. The proposed approach requirements are then emphasized. As well the necessity of quality management tools integration in decision making is concluded. Literature review highlights that each already existent quality tools satisfies partially these requirements. Among these latter FMEA is considered to be flexible and apt enough to be adapted to CAIP. Despite, improving points to FMEA are discussed and required modifications and future works are then proposed.
\end{abstract}

Keywords - Computer-Aided Inspection Planning (CAIP), Decision making, FMEA, Key characteristic (KC)

\section{INTRODUCTION}

During design stages, depending on designer's knowledge maturity, certain level of uncertainty is associated to the decision making. This is particularly true for a concurrent engineering context in which this paper focuses on process planning in a general viewpoint and inspection planning in particular. Manufacturing Process planning, and Inspection planning decisions seem to be more crucial since process and resources could engender non-functionalities to the product previously designed to fulfill the requirements. Product design is less subjected to decision making uncertainty than is process design.

Manufacturing process planning consists of determining the process and the selection of resources and equipment, essential to maintain crucial factors, manufacturing costs and product quality.

Subsequently inspection planning ensures not only the product quality but also the efficiency of manufacturing process. The conformity of product with respect to elaborated specifications will be verified by applying the product control. It also involves the detection of problems encountered during manufacturing. Thus, process monitoring is as well to prevent these latter.

Functionality of part, process or control, are thus interrelated in our point of view (compatibility of part / process-control / resource). The expected objective of this last design stage is to provide the best ratio between the efficiency of control/monitoring plan and the cost associated. It can be sustained by the techniques of Computer Aided Inspection Planning (CAIP).

\section{SCOPE DEFINITION AND MOTIVATION}

Inspection planning as an integral part of the design and manufacturing activities determines what characteristics of product are to be inspected, where and when [1]. Rather than products conformity control as a means of acceptance or rejection, in-process inspection to monitor the production, guaranties as well the quality. Effective decision support tools are inevitable to respond to the increases of product and production complexities.

The papers objective is to propose a decision support approach to CAIP, in which first essential step consists of determining the criticality of process parameters, part characteristics and product functions which should be subject to control / monitoring (Fig. 1). The approach is issued of three main questions: What to control? How to control? When to control? This paper is addressed to respond to the first question, the identification of key characteristics, by proposing appropriate tools to do so.

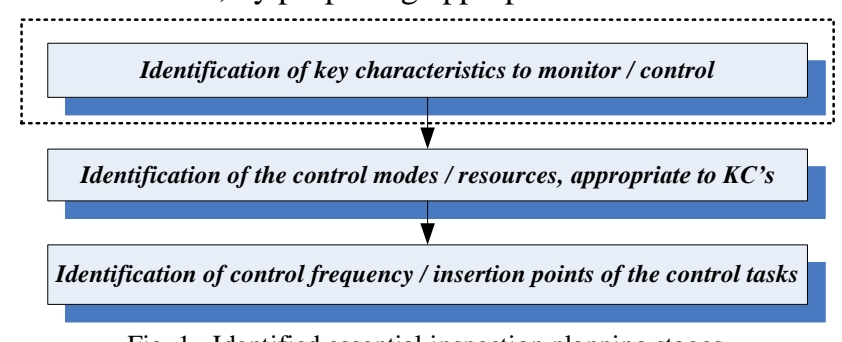

Fig. 1. Identified essential inspection planning stages

Quality management tools which permit us to identify crucial factors, associated to elevated non-functionality risk level, for product quality are desired to be integrated in proposed CAIP approach. As a solution, inspection planning associated to an adapted failure modes and effects analysis (FMEA) tool is analyzed to prioritize the associated risks. The subject which is usually treated is the failure rate minimizing through an efficient process control plan and not necessarily the product control plan. In this article product and process control planning are desired to be carried out in a concurrent way.

\section{CAIP ESSENTIAL REQUIREMENTS}

An optimal inspection plan is influenced by the choice of resources that provide certain level of accuracy (leads to quality) and demand certain frequency (cost investment). We do believe that the relevance of decision 
making in inspection process generation is also affected by the identification of potential / critical failure modes.

Thus in proposed approach to inspection planning, three essential consecutive stages are established (Fig. 1):

1) Identification of key characteristics to monitor / control: Parameters and characteristics which need more investment and precision due to their criticality to ensure the product quality are desired to be selected. The goal is to manipulate an affordable number of key characteristics to control / monitor. The interest is to limit the control to strictly necessary. Risk prioritization on $\mathrm{KC}$ 's, strongly impacts the inspection required frequency and accuracy.

2) Identification of the control modes / resources, appropriate to $K C$ 's: We aim to identify the conformity control / process monitoring modes and associated resources the most appropriate whose variations are inherent to the KC's selected in the previous stage. Decisions in this stage determine particularly the inspection's accuracy level but it would provide as well an intuition of required frequency.

3) Identification of control frequency / insertion points of the control tasks: Having already identified the $\mathrm{KC}^{\prime}$ s and the appropriate control modes, we seek to allocate the control tasks frequency control. Being given the detailed manufacturing process plan, inspection resources' performance (cost, risk, uncertainty ...) indicate the insertion points of control tasks in this manufacturing process plan. These points would be those where control uncertainty is elevated or tight tolerance intervals are to be maintained. The more the inspection is efficient, the less frequent it is.

Through this paper we focus on the first stage in which product characteristics to control and process parameters to monitor should be defined.

An assumption of this study is to correlate the causes (the interest of process monitoring) and effects (ensured by control conformity). It leads us to concurrent planning of process monitoring and conformity control tasks. It also enables us to reduce the cost of control, relating the selection of manufacturing process and control activities.

This is based on the concept of "key characteristics" [2], while the key properties could be situated at product, part, manufacturing process, and resources levels. They impact significantly the final cost and performance when the KCs differ from target values.

The multi-level aspect and causal correlations between the KC's are few addressed in the literature. Despite a developed assumption here is the possibility of having control and monitoring tasks at different levels (part, functional product, process, resource). The final satisfaction of customer does not rely solely on characteristics but also on functionality of product [3].

The objective is then to prioritize the relevant characteristics and parameters with significant impacts on product functionality. The same approach in this design stage is as well dominant in certain decision making tools for process planning. In next section adaptability of these latter to the proposed consecutive decision making (DM) for inspection planning, is criticized.

\section{DECISION MAKING FOR PROCESS PLANNING}

It is necessary to know whether the tool treats causality between the functions, characteristics and parameters. In this case, causality links could be qualitative or quantitative and so with more precision. One of the requirements to adapt these tools into inspection planning is to limit the risk prioritization to measurable and quantifiable functions, characteristics and parameters. Otherwise conformity control or process monitoring won't be feasible.

Through traditional FMEA, principal aim of FMEA is to rank the potential failure modes by using risk priority numbers (RPNs) and evaluate the causes and effects of different failure modes, to eliminate or reduce the chance of failure occurrence. To do so three risk factors occurrence $(\mathrm{O})$, severity $(\mathrm{S})$ and detection (D) are to be evaluated using an integer scale 1-10. Thus it is usually difficult to be precise based on this scale type. Final decision making turns out to be subjective and engender the uncertainty due to multiplication of these three factors.

To avoid the subjectivity in determining the risk priorities, according to an exhaustive literature review by [4], general drawbacks are distinguished and categorized:

- The relative weight among O,S and D cannot be taken into consideration in a decision making context.

- Despite the different risk implication and combination of $\mathrm{O}, \mathrm{S}$ and $\mathrm{D}$ the same value of RPN, could be obtained (this is particularly true while a higher risk value compensate a lower one and leads to a less elevated RPN).

- The mathematical formula (multiplication) for calculating RPN is questionable and debatable (for the reason described above).

- The mathematical for calculating the RPN is sensitive to variations in risk factor evaluations.

- The risk factors are difficult to be precisely estimated (usually the proposed solution includes the scale modification to increase the precision).

- Causality relationship among various failure modes and effects are not taken into account.

To confront these drawbacks, various risk estimation methods are proposed:

- Artificial intelligence (Rule-base system ...)

- MCDM (AHP/ANP ...)

- Integrated methods (AHP-Fuzzy rule-base System ...)

- Mathematical programming (Linear programming ...) They usually treat multiple problematic and so compensate at the same time various drawbacks. For instance scale modification for risk estimation is usually combined by rule-based method or decision making tool.

QFD is as well a structured approach for translating customer requirements to the product design in terms of technical characteristics, part characteristics and manufacturing processes parameters [7]. The causality relationships remain qualitative in QFD and thus judgments are limited to importance level of key characteristics. Through the literature, customer satisfaction is usually introduced as the goal of QFD. This 
is thus suitable for product design, but not necessarily for the process planning.

FMEA and QFE are risk management tools that provide decision guidelines to product development in achieving a design respecting the cost and the quality [8].

[9], proposed a tool inspired by QFD which covers its drawbacks. Impact matrix is used to generate a control / monitor plan with the constraints of concurrent engineering. Based on the evaluation of occurrence, severity and detection, criticality of failure modes are determined. Inspection plan is then proposed. Last stage consists of an assessment of the predictive quality of the product ensured by the proposed inspection plan. Contrarily to QFD, concerning the causality links, here impact level (sensitivity) is discussed. The judgments are so more precise and credible.

Another particularity of Impact matrix is the functions dissociation to (which is not the case in QFD):

- A system functionality awaited by the customer

- Function guaranteed by a condition of use suitability

- An assembly condition or more generally a function expected by the post-production stages

It treats at the same time customer requirements and elementary functions, treated in different stages of QFD.

Failure is the disappearance or degradation of a function. So to find potential failures one must know the functions. In this paper the objective is not to correct the failures but to avoid their occurrence to ensure the realization of functions. Thus from an optimistic view point and in an attempt to relating multi-levels causes and effects, KC flow down, as a hierarchy of most sensitive requirements associated to product, process or even resources, is developed. The high-level requirements are not achieved unless the KC's of low-level are satisfied. It states the product decomposition and quantifies the relationship between KC's as the equations or rules. Our approach takes into account these causalities.

Among these tools, FMEA seems to be capable to fulfill partially the inspection planning needs indicated at the beginning of this section. Contrary to common use of this tool, which is to set-out the corrective actions due to occurrence of non-functionalities, inspection planning tends to avoid this latter, elaborating an optimal control / monitoring plan. Certain modifications to adapt FMEA into inspection planning are proposed through this paper.

\section{ADAPTED / PROPOSED FMEA}

Proposed approach to FMEA is restricted to measurable and quantitative causes and effects, regardless of FMEA level of application. This will be as well true for the functions identified to be satisfied at product level.

1) The factors to estimate: As discussed in section 2.1, the aim is to identify the KC's at product, part or process level to assess the inspection plan. Thus in first stage of inspection process design there is no interest in determining the detection rating cause this latter is to be determined in second 2.2 and third 2.3 stages of proposed approach. Once relevant KC's have been classified, they would indicate the required capability of inspection resources and the frequency of control / monitoring tasks.

On the other hand while determining the failure occurrence; it would be due to capability of production resources which ensure the product quality. So it would be preferable to discuss the difficulty level of realization associated to characteristics and functions instead of failure occurrence. Realization difficulty makes more sense from a process planning point of view.

Contrariwise, severity remains a concept on which the decision making in this proposed approach is relied. Severity of low-level characteristics, knowing their relevant impact on the functions and difficulty level of their realization, leads us to determine the severity of high-level functions.

2) The overall risk estimation / propagation: For decision making, classical approach to FMEA determines the overall RPN based on the combinations of $\mathrm{O}, \mathrm{S}$ and $\mathrm{D}$. This may generate an identical value of RPN, for different set of O-S-D while each of them would require different decision. Consequently, characteristics or functions associated to high-risk level would be disregarded. The belief is that elevated risk levels on each factor should totally differentiate the established strategy. The criticality of parameters or characteristics is then proposed to be judged based on the risk associated to two factors separately; 'Realization difficulty' and 'Severity'.

This is to avoid identical risk priorities despite different risk level of factors. For each of them risk level should be determined.

3) FMEA structure and decomposition: As described before, inspection planning viewpoint leads us to rather talk about consequences and origins than effects and causes. Furthermore origins consist of direct and indirect columns. For instance to realize a product function, certain part functions (direct origin) need to be met due to the satisfaction of certain part characteristics (indirect origin). As well to meet part functions, process operation (direct origin) encompasses process parameters (indirect origin).

4) Decision making: Decisions are to be taken using heuristics which permit to interpret the factors relevance. From inspection planning viewpoint, heuristics lead us to:

- Control the functions of high-level while severity is associated to an elevated risk level and realization difficulty does not seem crucial.

- Control / Monitor the low-level part characteristics / process parameters' dispersion while realization difficulty represents an elevated risk contrary to the severity.

While designers tend to determine the risk level of factors, the judgments are solely qualitative and so considered as subjective due to scales, sometimes difficult to be precisely applied in the real-world cases [10]. As well decision making seems impossible because heuristics, corresponding to risk level, are not sufficient. Usually decision making is the discussed subject of 
previous works (often treated by fuzzy-based approaches) for risk prioritization. This is while the aim is not only to take into account the expert knowledge ambiguity and qualitative or imprecise information, but also to represent adequately and evaluate the uncertainty. This is to say that risk analysis and uncertainty management are indispensable for process planning. These two latter might be integrated into FMEA.

- Risk analysis: Possible causes of non-functionalities associated to their importance are desired to be determined.

- Uncertainty management: Uncertainty of information provided by experts is desired to be taken into account for final decision making. In other words, uncertainty associated to this risk level attribution is to be represented.

In such a situation the designer should be asked to be more precise on their risk evaluations. Thus authorized uncertainty will be rescued and judgment will be consequently more refined.

\section{EXAMPLE ILLUSTARTION / APPLICATION}

In this section modified FMEA is illustrated. Erreur ! Source du renvoi introuvable. consists of three levels of this latter: functional product, part and process levels. FMEA table structure is decomposed to 7 columns. Let's start with Product level:

1) Functions associated to product at assembly level are desired to be identified. For FMEA part this would be the elementary technical functions associated to the part. These functions are inherent to assembly functions. Naturally for each part of the whole assembly, an FMEA table should be treated.

2) As discussed before, one of the assumptions is to limit the study to measurable characteristics, functions and parameters. This quantifiable element associated to its control criteria is awaited to be described in this step.

3) Consequences at each FMEA level, are the translation of current characteristics' impact on high level functions. The dare for the designers is to express to what extend the higher level functions (consequences) are impacted by the current component. An outstanding point for the first level of FMEA is that there will be no highlevel function for assembly level. At second and third level of FMEA, consequences are considered as the functions treated in the table of higher level (Erreur ! Source du renvoi introuvable., A / B). The most relevant quantifiable characteristics or parameters corresponding to the part or operation are so appealed from previous table as control criteria for current table (Erreur ! Source du renvoi introuvable., C).

4) Origins (causes in traditional FMEA) consist of characteristics or parameters that impact the current studied function. We dissociate these latter into direct and indirect origins. At product level direct ones will be low level part elementary functions associated to different parts. For second FMEA origins will be process operations which ensure the realization of part functions. They might be associated to multiple operations. The relevance impact associated to origin, satisfying the higher level function is needed to be estimated. On other words direct origins at product level are considered and transferred as current treated element at part level (Erreur ! Source du renvoi introuvable., B). Their levels of impact on the consequences are also taken from previous level (Erreur ! Source du renvoi introuvable. D).

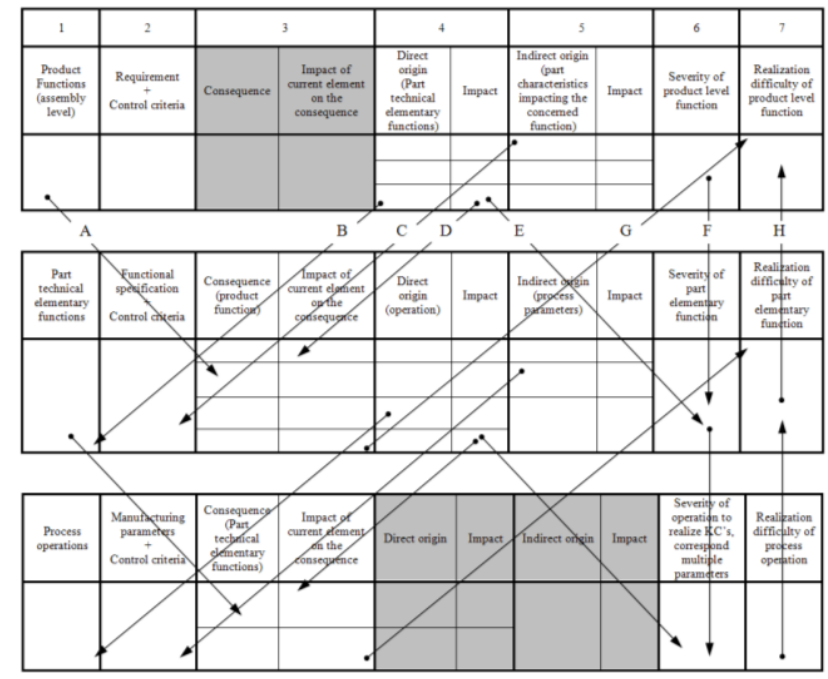

Fig. 1. Modified FMEA structure, three levels, Product / Part / Process

5) Indirect origins are considered as the components attached and essential to direct origins (ex. Multiple parameters associated to an operation). Part characteristics are indirectly impacting the product functions through the realization of elementary part functions

6) Severity of current product function at first level of FMEA should be expressed by the designer through this step. At part level to determine the severity of elementary functions, the severity of product's function estimated at previous level and relevance of concerned part function on the product function will be required (Erreur ! Source du renvoi introuvable., E / F).

7) This last step consists of attributing the risk associated to the realization difficulty of current function or process. But exceptionally at product level this would be determined based on the realization difficulty of part elementary function at second level which will be as well determined from the realization difficulty of process operation (Erreur ! Source du renvoi introuvable., H). At process level, this risk factor in proposed approach is usually the translation of process capability level (it is directly linked to the occurrence of defected parts and thus leads to product non-functionality) and easy to estimate. To do so, the relevant impact of lower level components corresponding to current part or product function is also required (Erreur ! Source du renvoi introuvable., G).

In this section the accomplishment of modified FMEA was described. Once these three levels are fulfilled, the knowledge provided by designers must be 
exploited to distinguish the key characteristics and attribute the level of control (product function, part elementary technical function, process parameters) to these latter. The judgment will be subjected to realization difficulty and severity of functions and characteristics. As explained and illustrated in Erreur ! Source du renvoi introuvable., severity is propagated descending the levels (product, part, process) while realization difficulty is estimated and propagated upward.

From a general viewpoint, the decision making heuristics are based on estimated weights for these two latter. In the case in which severity of function is judged as elevated while realization difficulty is low, the preference is to have the control at higher level product function (and not at elementary part function). Otherwise elevated realization difficulty leads us to control or to monitor lower level characteristics or process parameters. Both conformity control and process monitoring could be proposed, being given two factors moderately elevated.

\section{CONCLUDING REMARKS / PERSPACTIVE}

This paper proposed a new approach to CAIP. Regarding the common objective of FMEA, the possibility of integrating this latter into inspection through proposed approach was as well analyzed. There is an essential similarity point between these two which is identification of characteristics and parameters, crucial to the final quality of product. This approach covers certain points categorized by [4], described in section 4 .

Through traditional FMEA corrective actions are proposed at multiple levels while failure modes come to happen. This is while an optimal inspection plan tends to avoid the occurrence of failures. Conformity control of product or process monitoring tasks would be proposed. As illustrated in Erreur! Source du renvoi introuvable., a rule-based decision making based on two factors, severity and realization difficulty, was discussed which permits us to judge the consequences of high risk levels, associated to the factors, separately with no need to apply the aggregation methods.

By the way FMEA structure permits us to take into account the causality relationships between product and part functions, part characteristics, and process and resource parameters. Experts are awaited to establish these links rather than severity and realization difficulty assessment. These causality links are desired to be explicit and then supported by sensitivity assessment. This is while characteristics' impact on high level functions remains usually implicit and qualitative.

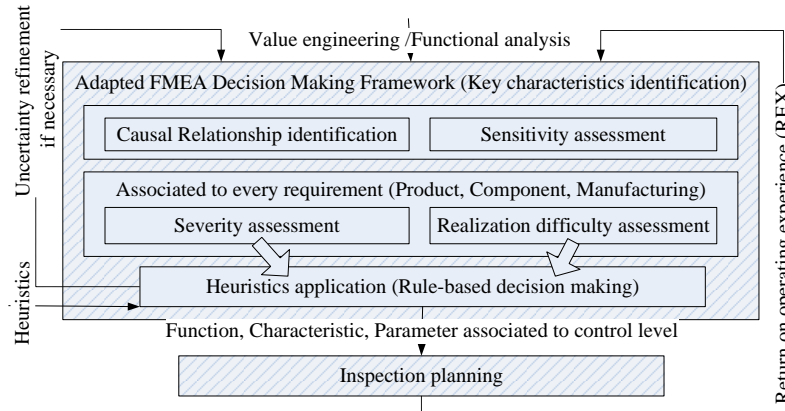

Fig. 2. Adapted FMEA decision making core to inspection planning

While designers are brought to be expressed for risk prioritization, qualitative decision making engenders risk analysis. In the case in which decision making through risk factor levels turns out to be imprecise due to a lack of information, uncertainty integration becomes inevitable. Future works are rather to improve the decision making precision, integrating uncertainties and return on operating experiences (feedbacks from inspection, on risk assessment and determined causal links). In inspection planning context for a dynamic environment, the belief is that in, continuous feedbacks improve the risk estimation.

The approaches already implemented to treat this risk analysis through contributed modifications to FMEA, usually does not take into account the uncertainty. In risk assessment context, knowledge on factors is often imprecise or incomplete and subjective [13]. Thus appropriate uncertainty representation methods according to the granularity of available information (possibility of achieving the precision) and required precision (necessity of increasing the precision) using the notions of possibility or probability are desired to be carried out. We also desire to obtain a classification of KC's based on the aggregation of both two decision factors. They should be then issue of the same scale. Another way to increase the precision is to modify the assessments scale. The quotation modification depends on expert knowledge maturity. As the last further work, this study can be extended also to other aspects of manufacturing process planning in the context of concurrent engineering.

\section{REFERENCES}

[1] F. Zhao, X. Xu, and S.Q. Xie, "Computer-aided Inspection Planning - The State of the Art", Computers in Industry, vol. 60, pp. 453-466, 2009.

[2] A. C. Thornton, "Engineering Design A Mathematical Framework for the Key Characteristic Process", Research in Engineering Design, vol. 11, no. 3, pp. 145-157, 1999.

[3] M. Pillet, "Appliquer la maîtrise statistique des processus (MSP / SPC)", 4th edition, Paris, Ed. D'organisation, 1994.

[4] H-C. Liu, L. Liu, N. Liu, "Risk evaluation approaches in failure mode and effects analysis: A literature review", Expert Systems with Applications, doi http://dx.doi.org/10.1016/j.eswa.2012.08.010, 2012.

[7] B. Prasad, "A concurrent function deployment technique for a workgroup-based engineering design process", Journal of Engineering Design, vol. 11, no. 2, pp. 103-119, 2000. 
[8] A. Hassan, A. Siadat, J. Y. Dantan, P. Martin, "Conceptual process planning - an improvement approach using QFD, FMEA, and ABC methods", Robotics and ComputerIntegrated Manufacturing, vol. 26, no. 4, pp. 392-401, Aug. 2010.

[9] M. Pillet, V. Ozouf, A. Sergent, and D. Duret, " La matrice d'impact pour construire un plan de surveillance avec les contraintes de l'ingénierie simultanée”, CPI, Rabat, Maroc, 2007.

[10] Z. Zhang, X. Chu, "Risk prioritization in failure mode and effects analysis under uncertainty", Expert Systems with Applications, vol. 38, no. 1, pp. 206-214, Jan. 2011.

[13] C. Baudrit, "Représentation et propagation de connaissances imprécises et incertaines: application à l'évaluation des risques liés aux sites et aux sols pollués" Ph.D. dissertation, Informatics Eng., l'université de Toulouse III Paul Sabatier, France, 2005. 